\title{
La destrucción del libro en Valparaíso, 1973
}

\author{
Marjorie Mardones Leiva* \\ Tania de Armas Pedraza*
}

Artículo recibido:

17 de septiembre de 2019

Artículo aceptado:

22 de enero de 2020

Artículo de investigación

\section{Resumen}

Comprender las memorias sobre las prácticas de eliminación y destrucción de libros "peligrosos" en la región de Valparaíso durante la dictadura militar de 1973 en Chile adquiere potencial impacto, considerando que los estudios sobre las prácticas de destrucción del libro, control editorial y allanamiento de las bibliotecas son casi inexistentes en la literatura nacional. El presente estudio pretender contribuir con su propuesta a replicar la investigación en otros contextos, nacionales e internacionales, y ampliar la producción de memorias sobre la temática. La metodología empleada es de tipo cualitativa y enfatiza en la comprensión de las memorias como

* Universidad de Playa Ancha, Facultad de Ciencias Sociales, Chile

marjorie.mardones@upla.cl tania.dearmas@upla.cl

INVESTIGACIÓN BiBLIOTECOLÓGICA, vol. 34, núm. 84, julio/septiembre, 2020, México, ISSN: 2448-8321 pp. 169-183 
procesos subjetivos anclados en experiencias, en marcas simbólicas y materiales en objeto de disputas, conflictos y luchas. Como técnicas de producción de información se empleó el análisis de documentos y las entrevistas cualitativas. Los resultados de la investigación se produjeron a través del análisis de contenido cualitativo, generándose categorías analíticas y emergentes que permitieron describir las prácticas de destrucción de libros y el contexto de realización.

Palabras clave: Destrucción del Libro en Chile; Biblioclastía; Memorias Sociales; Historia del Libro en Chile

The books' destruction in Valparaíso, 1973

Marjorie Mardones Leiva and Tania de Armas Pedraza

\begin{abstract}
Understanding the reports over the practices of elimination and destruction of dangerous books in the Valparaíso region during the 1973 military dictatorship in Chile, acquires potential impact, considering that studies on the practices of book destruction, editorial control and Library confiscation are almost nonexistent in national literature. The present study intends to contribute with its proposal to replicate research in other contexts, national and international, and expand the production of reports on the subject. The methodology used is of a qualitative type and emphasizes the understanding of memories as subjective processes anchored in experiences, in symbolic and material marks; in object of disputes, conflicts and struggles. As information production techniques, document analysis and qualitative interviews were used. The results of the research were produced through qualitative content analysis, generating analytical and emerging categories that allowed describing the practices of book destruction and the context of realization.
\end{abstract}

Keywords: Destruction of the Book in Chile; Biblioclasty; Social Memories; History of the Book in Chile 
— $\mathrm{n}$ Chile, los estudios de la destrucción del libro (prácticamente inexisEtentes) adquieren un significativo valor: es la perspectiva de la memoria la que permitiría evocar y significar desde el presente el proceso de su eliminación en territorios determinados, como la región de Valparaíso, y al mismo tiempo, captar la significación que la ciudadanía actualmente le otorga al libro y todo aquello que lo circunda.

Para la reconstrucción de este episodio del libro destruido en Valparaíso, Chile, adquieren vital importancia tanto fuentes documentales (como lo son los recortes de prensa, decretos universitarios, entre otros) como los testimonios y relatos anónimos.

La propuesta general de este artículo gira en torno a la comprensión de estas memorias sobre las prácticas de eliminación y destrucción de libros considerados "peligrosos" en la región de Valparaíso durante la dictadura militar de 1973. Con base en ello, resulta relevante la propuesta de Jelin (2002), quien se refiere al trabajo de memoria para destacar el rol activo y productivo que tienen los sujetos al significar el pasado, distinguiéndolo de la simple repetición del mismo. En tanto prácticas sociales, las memorias analizadas no sólo contribuyen a historizar sucesos pasados en la región, sino que también permiten disputar los modos de significar esos sucesos, tensionando críticamente el presente y los espacios cotidianos desde donde hoy en día se construye politicidad (Piper, 2005).

Como parte de la teorización interdisciplinaria que aborda el enfoque de la memoria destaca, por su influencia en América Latina, la perspectiva de Stern (2009), quien propone una mirada histórica que contribuya a comprender la articulación dinámica entre tipos de memorias: las emblemáticas y las personales o sueltas. Stern se refiere a su definición de nudos de memoria en cuanto a seres humanos y circunstancias sociales que exigen que se construyan puentes entre el imaginario personal y las memorias emblemáticas. La memoria emblemática puede ser definida como un marco que va incorporando, dando sentido y organizando las memorias personales. Esta definición se articularía con la perspectiva sociológica de Halbwachs, quien enfatiza en los aspectos sociales para la producción de dichas memorias (Lavabre, 1998).

\section{Metodología de LA investigación}

Esta investigación, diseñada desde una metodología cualitativa participativa, enfatiza en la comprensión de las memorias como procesos subjetivos 
anclados en experiencias, en marcas simbólicas y materiales; en objeto de disputas, conflictos y luchas. Fueron empleadas dos técnicas para la producción de datos: el análisis documental y la entrevista cualitativa.

Respecto al análisis documental, se revisaron diarios de la época, archivos documentales y fotografías provenientes de las hemerotecas de la Biblioteca Nacional, de la Biblioteca Santiago Severín y del Centro Documental del Museo de los Derechos Humanos.

Las entrevistas se aplicaron para producir relatos sobre las prácticas de destrucción y eliminación de libros en el contexto de la dictadura de 1973, en la región de Valparaíso: se produjeron 40 entrevistas, cinco relatos recuperados en formato audio y cinco filmaciones, obteniendo 50 testimonios para el análisis de contenido. Se realizó para ello un proceso de codificación cualitativa de las entrevistas y los documentos, avanzando hacia una descripción e interpretación cualitativa.

\begin{tabular}{|c|c|c|c|}
\hline No. & Categorías/Subcategorías & Códigos & Códigos emergentes \\
\hline 1 & \multicolumn{3}{|c|}{ Caracterización general } \\
\hline 1.1 & $\begin{array}{l}\text { Perfil del entrevistado, } \\
\text { entrevistada }\end{array}$ & $\begin{array}{l}\text { Edad } \\
\text { Ocupación } \\
\text { Militancia política } \\
\text { Sexo }\end{array}$ & Militares \\
\hline 1.2 & Tipología documental & $\begin{array}{l}\text { Libros } \\
\text { Revistas } \\
\text { Fotografías } \\
\text { Otros }\end{array}$ & $\begin{array}{l}\text { Murales } \\
\text { Panfletos } \\
\text { Discos }\end{array}$ \\
\hline 2 & \multicolumn{3}{|c|}{ Prácticas de destrucción de libros } \\
\hline 2.1 & Formas de destrucción & $\begin{array}{l}\text { Quemas } \\
\text { Entierros } \\
\text { Allanamientos }\end{array}$ & $\begin{array}{l}\text { Clandestinidad } \\
\text { Venta } \\
\text { Recuperaciones } \\
\text { Robos } \\
\text { Fagocitaciones }\end{array}$ \\
\hline 2.2 & $\begin{array}{l}\text { Recuperación y preservación } \\
\text { de obras }\end{array}$ & $\begin{array}{l}\text { Desentierros } \\
\text { Hallazgos casuales } \\
\text { Circulación de } \\
\text { obras clandestinas }\end{array}$ & \\
\hline 2.3 & Repertorio bibliográfico & $\begin{array}{l}\text { Autor, autora } \\
\text { Título de la obra } \\
\text { Editorial }\end{array}$ & \\
\hline 3 & \multicolumn{3}{|c|}{ Contexto } \\
\hline 3.1 & Personas involucradas & $\begin{array}{l}\text { Familiares } \\
\text { Militares } \\
\text { Amigos }\end{array}$ & \\
\hline
\end{tabular}




\begin{tabular}{|c|l|l|l|}
\hline 3.2 & Lugares & $\begin{array}{l}\text { Espacios públicos } \\
\text { Espacios privados }\end{array}$ & $\begin{array}{l}\text { Quebradas } \\
\text { Librerías } \\
\text { Bibliotecas }\end{array}$ \\
\hline 4 & \multicolumn{3}{|c|}{ Categorías emergentes } \\
\hline 4.1 & Valor simbólico del libro & $\begin{array}{l}\text { Expresiones para } \\
\text { referirse al material } \\
\text { impreso. } \\
\end{array}$ & $\begin{array}{l}\text { Expresiones que } \\
\text { refieren el aconte- } \\
\text { cer personal con } \\
\text { los hechos. }\end{array}$ \\
\hline
\end{tabular}

Tabla 1. Matriz de categorías y códigos para la codificación e interpretación de los datos

\section{Presentación y ANÁlisis de Resultados}

\section{Caracterización general}

La muestra recoge relatos de hombres y mujeres, la mayoría jóvenes menores de 20 años al momento del golpe militar, quienes fueron protagonistas de los hechos o bien son familiares directos que presenciaron los acontecimientos; se consideraron los testimonios tanto de militares que tuvieron un rol activo en la destrucción de libros y material impreso como de víctimas directas de esa destrucción, por lo general militantes de agrupaciones opuestas al régimen autoimpuesto.

Respecto a la caracterización del material destruido, es posible señalar que correspondía a la más diversa tipología documental: libros, fotografías, discos, revistas, panfletos, diarios, folletos, afiches, documentos en general, lo cual coincide con los recortes de prensa de la época. En este sentido se incorporó la idea del blanqueamiento cultural relatado en El Golpe Estético (Errázuriz y Leiva, 2012), borrando también la muralla y otros símbolos que aludieran a ideas consideradas subversivas: "Saquearon y se llevaron todos los libros en camiones, todo sin ninguna distinción. Todo lo que fuera material cultural: afiches, publicidad, discos de música" (E20).

\section{Prácticas de destrucción de libros}

Las formas y prácticas de destrucción del material en la época son variadas. Los códigos establecidos para el análisis, como indica la Tabla 1, se centraron en quemas, entierros, que emergieron como nuevos códigos tales como robos, ventas ilegales, supresión (fagocitar, romper, camuflar), abandono de 
material; todas acciones realizadas algunas veces producto del miedo imperante, del peligro que podrían significar esos materiales o por acción directa de terceros. La mayor parte de estos testimonios tienen un correlato con lo publicado en los recortes de prensa de la época.

En los relatos, la práctica más común era la quema de libros:

Me contó que sus padres estaban quemando los libros. Me dijo que los había escuchado hablar algo de que estaban allanando la casa de sus amigos y que tendrían que quemar los libros. El vio que además de sus libros estaban quemando muchos papeles sueltos, supuse que serían algún tipo de documentos. Fue ahí cuando recuerdo que me dijo textualmente: Patty, quema todos los libros si no quieres que te maten... ese mismo día por la noche, cuando mis papás estaban acostados, agarré todos los libros, los meti en un saco papero y los fui a dejar a la quinta, donde los quemé todos juntos. (E4)

Otra práctica de destrucción recurrente la constituyeron los entierros de material impreso:

Lo que sí me acuerdo es que quemaron varios libros que tenía, en verdad no sé lo que tenían los libros. Igual yo era chico pero sí me acuerdo que los quemaron... pero igual hubo algunos que los guardaron. Todavía yo me acuerdo cuando mi papá bizo un boyo en el patio, por ahí donde había varios árboles. (E5)

En el caso de los allanamientos, documentados en detalle en la prensa local, se condice con los relatos de la muestra:

Recuerdo que en el patio estaban todos los detenidos con las manos en la nuca y la frente en el suelo, en fila. Los marinos pasaban con la cara cubierta verificando que estaban en una buena posición, si no la persona que estuviera chueca la golpeaban. Ahí llegaron camiones repletos de libros, producto de los allanamientos que hacían en casas y escuelas. (E16)

En la prensa de la época, los allanamientos aparecen consignados en el diario La Estrella de Valparaíso del viernes 14 de septiembre de 1973, con el titular "Infantes de Marina allanaron campamento":

Durante varias horas del día de ayer, fuerzas de Infantería de Marina realizaron una operación de allanamiento en el Campamento Salvador Allende de Viña del Mar [...] Junto con el retiro de material explosivo y material de propaganda política, fueron detenidos algunos habitantes de esta población. 
Importante en los testimonios fue el reconocimiento de robos de libros:

En ese tiempo la casa [La Sebastiana, donde vivía el escritor Pablo Neruda] fue allanada muchas veces, pero después del golpe, cuando ya no había gente viviendo, allí entraron los militares y vaciaron la biblioteca y rompieron, quemaron, robaron. Desapareció prácticamente la biblioteca. (E17)

La cosa es que no fue solo la mía sino las librerías fueron saqueadas, se dice que no todos se destruyeron sino que algunos fueron robados y libros quedaron guardados. (E20)

Dos relatos en primera persona hablan de que tuvieron que comerse los documentos, que indudablemente son otras materializaciones del libro, lo que da cuenta de lo extremo de la experiencia:

Nos hicieron vaciar los bolsillos y poner todo en frente de las manos, y un pa$\mathrm{co}^{1}$ me viejo vio $[\mathrm{sic}]$ que tenía un carnet de partido de las juventudes comunistas. El carabinero me dijo - Cómetelo. Y me lo tuve que comer. (E3)

Pensé que si me movía los libros caerían y eso concentraría la atención en los libros y podría tomar el paquete de papeles y comérmelos, que era la única forma de hacerlos desaparecer o al menos destruir la información que contenían. Y así sucedió. Me acomodé para provocar la caída de los libros y cuando todos se volvieron a ver lo que pasaba, yo agarré el fajo de papelillos y me los tragué. (E30)

En el caso de los discos, los quebraron para destruirlos:

Cuando yo salí, tomé mi disco y me lo traje. Era un LP de la Cantata de Santa María de Iquique, pero igual lo destruí en los albores de la dictadura. Primero lo escondí, lo anduve paseando conmigo, me atreví a andarlo trayendo y a viajar con él. Después lo quebré. (E3)

Así mismo lo relata el diario El Mercurio de Valparaíso del domingo 16 de septiembre de 1973, con el titular "Marxistas asustados abandonan libros y textos en las calles":

En las [...] partes altas y pie de cerros, centenares de comunistas, socialistas y otros proclives a la Unidad Popular, están abandonando sus literaturas hasta hace poco predilectas, y es así como cientos de folletos y libros concientizadores están siendo abandonados por sus dueños marxistas en las puertas de las casas o en las

1 Paco: forma despectiva de referirse a la policía pública. 
Allanan librerias de la zona.Marxistas asustados abandonan
libros y textos en las calles

Una gigantesca operación e incinerados para su destrucde limpieza en las librerías de ción.

propiedad de conocidos ABANDONAN LITERATURA comerciantes de tendencia izquierdista inició la Armada en su campaña de ir eliminando paulatinamente todo aquello que pueda servir para fomentar el odio y la división en la ciudadanía.

Camiones de la Prefectura Militar han estado allanando las_librerias sindicadas como marxistas. $f$ bantrerotsado miles de fib os y -liers sobre comunismo. revofución bolchevique, Cuba y Castro. Lenin. etc., la mayoria de procedencia de la Editorial Quimantú de editoriales cubanas.

Una vez en los vehiculos los textos marxistas son Jlevados
Pero no sólo las librerías del ramo se están deshaciendo de los textos con doctrina y filosofia marxista. mente en la Avenida Baquedano, partes altas y pie de cerros, centenares de comunistas. socialistas y otros proclives de Ta- Unidad Popular, están "abandonando" sus lite writahesta hace poco predifectas, y es así como cientos de folletos y libros concientizadores están siendo abandonados por sus dueños marxistas en las puertas de casas a en las aceras comu una manera de deshacerse de esta literatura.
En las calles, principal-
Los tranquilos moradores de las casas afectadas. en un comienzo se inquietaron con estos "depósitos" hećnos a la sombra de la noche, pero posteriormente se han organizado por sectores y han preparado grandes fogatas para quemar estos libros que fueron distribuidos por miles en las provincia de Valparaiso. y cuyos principales depósitos están siendo ubicados por la Intendencía.

Ia última librería allanada ayer por efectivos de Infantería de Marina fue la librería "Nueva Era" ubicada en los bajos del edificio donde funciona Almacenes "Cori" y en la cual se requisó un camión de 8 toneladas casi completo con propaganda marxista.

Figura 1. El Mercurio de Valparaíso, domingo 16 de septiembre de 1973 (Imagen de archivo)

En el diario El Mercurio de Valparaíso del jueves 20 de septiembre de 1973 apareció la nota titulada "Encuentran tres bolsas con propaganda marxista":

Tres bolsas con propaganda extranjera principalmente cubana y china, fueron encontradas en dependencias de telégrafos y correos.

Finalmente, si bien no constituye una práctica recurrente, este relato da cuenta de formas insospechadas que se utilizaron al hacer desaparecer los impresos:

Tenía mi propia biblioteca de libros, revista y documentos de la China comunista y de Rusia, y sabía que, si los encontraban en mi casa, era seguro que desaparecería como muchos otros de los distintos cerros de Valparaíso. Cuando llegué, en seguida los busqué. Recuerdo haber pegado una a una las páginas en la pared, saqué pintura negra y empecé a cubrirlo todo. Tenía miedo, pena, rabia. Lastimosamente, perdí todos mis libros ese día. Pero era una cosa por otra, ¿no? (E27)

Al analizar los repertorios bibliográficos destruidos, el Oficio 0160, Valparaíso 03 de marzo de 1975, incluye una lista de 60 libros con la orden de ser 
quemados a la brevedad, de propiedad de la Universidad de Chile, Facultad de Arte y Tecnología, y de particulares. Se hace alusión a este documento en el Oficio 0163, que señala: "Me permito poner en su conocimiento que, con fecha 5 de marzo, el suscrito debió proceder al cumplimiento del Oficio 0160 del Coordinador Administrativo de la Sede, Dr. Eduardo Quevedo Leiva, relacionado con la incineración de 60 libros pertenecientes a la Facultad de Arte y Tecnología”. Estos documentos, timbrados con carácter de Reservado en un tercer documento emitido desde Washington, D. C., con fecha 11 de agosto de 1975, por parte del Embajador de Chile en Washington y dirigido al Señor Ministro de Relaciones Exteriores (DINEX), fueron consultados por un requerimiento del periodista Joseph Spear, miembro del equipo del columnista Jack Anderson, quien fuera un destacado periodista internacional reconocido por su lucha contra la corrupción y cuya investigación dio origen al libro Documentos secretos de la ITT (Secretaría General de Gobierno, 1972). En dichos documentos, el Embajador consigna que:

Quisiera destacar el hecho de que esta es la segunda vez en cinco meses que la oficina de Jack Anderson obtiene documentos de la Universidad de Chile, Sede Valparaíso. Tal como informé en mi telex 282 y 325 de abril último, en esa oportunidad el periodista obtuvo formularios de inteligencia supuestamente utilizados en esa universidad.

Es el único documento localizado a la fecha que contenga un listado de títulos destinados para la quema. El resto de libros considerados peligrosos son los que las y los entrevistados señalaron, entre los que destacan la colección UTHEA casi completa, obras de Mao Zedong, libros de la Editorial Quimantú, "todo lo que fuera marxista o de contenido político" (E3). Se mencionan también libros, revistas y diarios del MAPU (Movimiento de Acción Popular Unitaria), libros de la colección "Nosotros los chilenos", Colección Minilibros, las revistas Cabrocbico y Paloma, y (nuevamente) todo el fondo de la Editorial Quimantú. Entre los títulos se mencionaron el Libro rojo de Mao, el Manifiesto Comunista, Vivir y morir de los pueblos mineros, de la Editorial Quimantú; discos del sello DICAP (Discoteca del Cantar Popular) y del sello Jota Jota. Particularmente se habla del disco La Cantata de Santa María de Iquique. Se mencionan el libro La interpretación marxista de la Historia de Chile, de Luis Vitale, libros y revistas de la China comunista y de Rusia, las obras El Socialismo Chino y Los principios del comunismo, así como la revista El Estatus del Partido Comunista de China. En El Mercurio de Valparaíso del domingo 16 de septiembre de 1973 se indica: "ban requisado miles de libros y folletos sobre comunismo, [...] Cuba y Castro, Lenin, etc., la mayoría de procedencia de la Editorial Quimantú de editoriales cubanas [sic]”. 
Sin embargo, un entrevistado que participó del aparato represor de la época agrega, respecto a los procedimientos de exterminio documental:

Libro que encontraban, lo sacaban. No lo analizaban, ninguna cosa. Entonces los echaban en los camiones y los llevaban a los cuarteles y procedían a quemarlos... nunca los analizaban. (E10)

Otros testimonios ratifican este hecho, señalando que llamaba la atención que parecía no haber selección alguna o indicaciones claras de qué destruir:

Entonces el oficial continuó revisando libros, en tanto yo pensaba cómo salir bien de la situación. Que no me descubrieran. Mientras, la fiebre seguía subiendo y subiendo... De un momento para otro el oficial se detuvo frente al libro Cibernética y Revolución Industrial. Duda por un minuto y me consulta ¿Usted sabe que es esto de la cibernética? Porque está el tema de la Revolución y eso es peligroso. Yo, como estudiante de la Santa María le explico lo que en esos años sabíamos del tema. Le digo que son los mecanismos que tienen un retorno de información para los procesos de control automático. El oficial acota: -Interesante, pero sospecho que es peligroso. El libro pasó a ser parte de los que se llevaron. (E30)

En los testimonios surgieron, a la vez que formas de destrucción de libros, los mecanismos para su preservación, desentierro y recuperación, al igual que los discos:

Milicos se llevaron y traspasaron la Universidad Federico Santa María. Otros milicos escondieron los libros en el sótano que hay en el Aula Magna. Cuando llegó la democracia se recuperaron los libros, pero 5 de cada 100 estaban en buen estado. (E1)

Este mismo hecho se relata en El Mercurio de Valparaíso, con fecha 21 de septiembre de 1973, con el titular "9 Toneladas de libros marxistas en la USM":

Hasta ahora han sido retiradas varias caminonadas de libros y folletos y, se continúa en la revisión de las diferentes dependencias de este establecimiento de educación superior $[\ldots]$ por otra parte ha llamado la atención el enorme grado de depreciación moral que al parecer allí existía a juzgar por el estado de las murallas, especialmente en las salas de clases, las cuales se encontraban cubiertas por escrituras que contenían las más increíbles groserías.

Las destrucciones de libros produjeron diversas consecuencias en la población, desde quemas colectivas y espontáneas hasta la búsqueda de fórmulas para la preservación de obras. Años después han comenzado los desentierros de libros y material en general: 
Los libros que enterramos allí casi una década hasta que mis hermanos Gonzalo y Guillermo los desenterraron. Fue una gran sorpresa ver que los libros se conservaron en muy buen estado y se repartieron entre los integrantes de la familia. Yo me encontraba en esa época en Punta Arenas y aún conservo de ese montón una revista de 300 fotos de Salvador Allende, que en estos momentos tengo en mis manos. (E14)

El hallazgo de los libros fue hace un año, un año y medio no más (año 2017). Revisando el dormitorio donde dormían mis padres, noté que había un madero que estaba suelto, no tenía clavos. Me llamó la atención y lo levanté y al sacar el madero, me encontré con estos discos que habíamos guardado nosotros. (E29)

Como se observa, aunque hubo personas que intentaron salvar los libros, fue inevitable en muchos casos su pérdida:

Bueno, afortunadamente no allanaron la casa nuestra pero los libros quedaron ahí. Después con el tiempo quisimos recuperarlos [...] lamentablemente habían desaparecido gran parte de ellos, ya que se los habían comido los ratones. (E22)

A estos marinos no les interesaba qué tipo de libro leías, sino que su objetivo era destruir todo lo que había dentro de la CUT llenos de odio fascista. (E16)

\section{Contexto}

Respecto al contexto en que se suceden los hechos, podemos señalar que la mayor cantidad de relatos se refiere al periodo entre los días 14 y 21 de septiembre de 1973, y los lugares citados en las casas son más bien en el living, patio y baño. En los territorios mencionados surgen recurrentemente las quebradas de Valparaíso, Viña del Mar, Quillota, La Calera. Los cerros mencionados son el Cerro Cordillera, Cerro Barón, Cerro Playa Ancha, Sector Marina Mercante de Playa Ancha, Cerro Placeres, Cerro Yungay, Parque Italia, Barrio O’Higgins, Villa Dulce de Viña del Mar, Campamento Salvador Allende de Viña del Mar, Forestal Alto.

Respecto a espacios públicos, figuran la Universidad Federico Santa María, la Escuela Naval, la CUT (Central Única de Trabajadores), Colegio de Quillota, librería Nueva Era, ubicada en calle Condell; Pérgola del Libro de Viña del Mar, ubicada frente a la plaza Vergara, el Campamento Camilo Torres de Viña del Mar, el diario La Unión de Valparaíso, la Biblioteca Municipal de Viña del Mar, y la Universidad de Chile, Facultad de Arte y Tecnología, sede Valparaíso. 
La última librería allanada ayer por efectivos de Infantería de Marina fue la librería "Nueva Era" ubicada en los bajos del edificio donde funciona Almacenes "Cori" y en la cual se requisó un camión de 8 toneladas casi completo con propaganda marxista. (El Mercurio de Valparaíso, 1973b)

[...] La cosa es que no fue solo la mía, todas las librerías fueron saqueadas, no solo destruyeron sino que algunos fueron robados y quedaron libros guardados [...] lo peor es que no solo allanaron, sino que también los persiguieron por ser gestores culturales de propaganda supuestamente política. Nosotros estuvimos una semana encerrados en la librería con candados de la armada [...] después los reventamos y seguimos funcionando por un año hasta que volvieron a allanar por lo cual finalmente cerramos, esta librería se llamaba Nueva era que se especializaba en ciencias sociales: Sociología, política, etc. [...] la gente tenía miedo de esconder los libros, era una acción que requería mucho valor. (E20)

\section{Categoría emergente: valor simbólico}

En esta categoría se han considerado los términos con los cuales se hace referencia a la documentación destruida en la prensa citada, los diarios La Estrella de Valparaíso y El Mercurio de Valparaíso, entre los días 14 y 21 de septiembre. Entre ellos destacan "material de propaganda política", "lecturas no aptas", "literatura marxista", "recursos terroristas", "literatura de concientización", "propaganda marxista", "propaganda extranjera", "propaganda política".

Finalmente, los comentarios personales dan cuenta de cómo se vivió este episodio de destrucción, desde las voces oficiales y las de los y las protagonistas que vivieron los hechos, donde el miedo aparece recurrentemente:

Lo que sí tiene importancia es el miedo, lo que sí tiene importancia es que este tipo de cosas no vuelvan a pasar [...] Me gustaría quedarme con ese pensamiento que alguien los pudo guardar y salvar de ser destruidos. (E8)

Los libros son referidos con una fuerte emotividad. Se recuerdan no por su materialidad o aspectos de edición, empaste, valor material, sino que se explicita recurrentemente su valor simbólico:

Cada uno tenía en su poder libros amados, libros que nos hicieron soñar y esperanzarnos con un gobierno del pueblo [...] Nuestros fieles y entretenidos compañeros en esos tiempos en que solo las personas más acomodadas tenían televisión y uno recurría a los libros. (E14) 
Por lo cual algo tan simple y profundo como un libro, que enseñara cualquier ideología distinta a la del régimen, sería eliminado o censurado [...] Lamentablemente mi abuelo, al descubrir lo que yo intentaba hacer, la retó muy fuerte (a la madre) y le quitó los libros, rompiéndolos y quemándolos en la cocina. (E21)

Considerando la importancia que tienen los libros hubo una frase que llamó mucho la atención y que en segundos recorrió todo Chile y que decía: hay que quemar todo lo que huela a marxismo - decían los militares, por lo tanto había un terror con respecto a las cosas que uno podía tener por gusto o por cultura y allí ocurrieron muchas quemas [...] llegaban y los tiraban a la calle y los quemaban ahí mismo, fue bastante triste. (E22)

Asimismo, los libros se valoraban como un objeto que podría provocar un cambio social importante: un elemento peligroso como un arma, peligroso para la dictadura que se comenzaba a imponer en el país:

En ese momento nos dimos cuenta que realmente no tenían claro lo que estaban haciendo. Lo hacían porque el libro en sí era una amenaza para la dictadura. El conocimiento de las personas era un arma mucho más grande que las que ellos tenían por lo que cosas como las canciones, poemas o libros podían ser un peligro. (E28)

\section{Conclusiones}

Las memorias producidas respecto a las prácticas de destrucción del libro y la lectura en Valparaíso constituyen un ejercicio de documentación de estas prácticas en el contexto dictatorial del Chile reciente. Retomando a Stern (2009), las memorias personales permiten articularse para complementar y disputar las memorias o relatos hegemónicos. Tal como este autor plantea, a través de estos relatos producidos emergen nudos de memoria: lugares, organizaciones, contextos espaciales específicos que objetivan desde el presente estas prácticas y disputan el valor simbólico del libro.

En la historia del libro en Chile, estos eventos han acontecido durante toda la historia local sin un reconocimiento o sistematización de los hechos. En estos contextos, tal como lo muestran los relatos, el libro es representando en su potencialidad de cambio social; de ahí el requerimiento de destrucción y despojo. Al destruir el libro no sólo se afecta una materialidad, sino que se atenta contra esta potencia que tienen las prácticas lectoras. Producir memorias sobre estas prácticas es también reconocer esta potencialidad transformadora, más allá de la descripción detallada de las prácticas de destrucción del libro desde el plano de lo simbólico. 
Esta investigación permitió producir memorias, que muestran que durante este periodo de la historia del libro en Chile no sólo se destruyeron materialidades, o prácticas escriturales (como los rayados de calle y murallas en general), sino que se actuó sobre algo mucho más frágil: la idea del libro como un espacio de libertad e identidad, por lo que este estudio busca comprender dicho valor simbólico del libro, el cual se entiende en un espacio de disputa que provoca dicotomías tales como control y democratización de la información.

Finalmente esta investigación propone un modelo replicable para revisar la historia social vinculada al libro desde una mirada crítica, observando los usos, procesos e impactos en las comunidades, y entendiendo que son dichas prácticas las que contienen perspectivas y miradas de mundo que sólo ocurren en ciertos contextos políticos y sociales y que es una de las razones de ser de instituciones como bibliotecas y museos, es decir, recuperar esas memorias olvidadas y negadas para ponerlas en valor y contribuir a la reconstrucción del tejido social.

\section{ReFERENCIAS}

El Mercurio de Valparaíso. 1973a. "En sus hogares está el personal de La Unión”, 14 de septiembre de 1973.

El Mercurio de Valparaíso. 1973b. "Marxistas asustados abandonan libros y textos en las calles". 16 de septiembre de 1973.

El Mercurio de Valparaíso. 1973c. "Estudiantes forman brigada de limpieza". 17 de septiembre de 1973.

El Mercurio de Valparaíso. 1973d. "Nadie negará el esfuerzo en desafío de reconstruir el país". 17 de septiembre de 1973.

El Mercurio de Valparaíso. 1973e. "Allanamiento de campamento "Camilo Torres" se hizo ayer". 17 de septiembre de 1973.

El Mercurio de Valparaíso. 1973f. "Operación limpieza cumplen Las FFAA en forma rigurosa”. 19 de septiembre de 1973.

El Mercurio de Valparaíso. 1973g. "Total limpieza se realiza en la Calera”. 20 de septiembre de 1973.

El Mercurio de Valparaíso. 1973h. "La Biblioteca era centro de literatura marxista". 20 de septiembre de 1973.

Errázuriz, Luis Hernán y Gonzalo Leiva. 2012. El golpe estético. Dictadura militar en Chile, 1973-1989. Chile: Ocho libros.

Jelin, Elizabeth. 2002. Los trabajos de la memoria. España: Siglo XXI España Editores.

Lavabre, Marie-Claire. 2001. “¿Se puede influenciar la memoria?” Cabiers français, La Documentation française 30: 8-13.

Lavabre, Marie-Claire. 1998. "Maurice Halbwachs et la sociologie de la mémoire”. Numéro thématique Mémoire et histoire, Raison présente 128 (4e trimestre): 47-56. https://doi.org/10.3406/raipr.1998.3504 
La Estrella de Valparaíso. 1973a. "Numerosos allanamientos se cumplió en Viña del Mar”. 14 de septiembre de 1973.

La Estrella de Valparaíso. 1973b. "Allanada Pérgola Del Libro En Viña”. 14 de septiembre de 1973.

Piper, Isabel. 2005. Memoria y derechos humanos, prácticas de dominación o resistencia. Chile: Ocho libros.

Secretaría General de Gobierno. 1972. Documentos secretos de la ITT. Chile: Editorial Quimantú.

Stern, Steven. 1998. "De la memoria suelta a la memoria emblemática: hacia el recordar y el olvidar como proceso histórico (Chile, 1973-1998)", en Las conmemoraciones: las disputas en las fechas "in-felices", comp. por E. Jelin, 11-33. Madrid: Siglo XXI.

Stern, Steven. 2009. Recordando el Chile de Pinochet: en vísperas de Londres 1998. Santiago de Chile: Universidad Diego Portales.

Urbizagastegui, Rubén. 1992. "El rol de las bibliotecas: un análisis de dos paradigmas sociológicos”. Investigación Bibliotecológica: archivonomía, bibliotecología e información 6 (12) (enero): 34-41. Fecha de consulta: 01 de octubre de 2019. http://dx.doi.org/10.22201/iibi.0187358xp.1992.12.3807

Para citar este texto:

Mardones Leiva, Marjorie y Tania de Armas Pedraza. 2020. "La destrucción del libro en Valparaíso, 1973”. Investigación Bibliotecológica: archivonomía, bibliotecología e información 34 (84): 169-183.

http://dx.doi.org/10.22201/iibi.24488321xe.2020.84.58178 